\title{
The Effect of the Shift in Professional Development Models on a Saudi Arabian University Context
}

Adil Abdul Rehman: Exeter University, UK.

ABSTRACT: This article discusses the shift in professional development models from inspectional to collegial systems and the effect of this trend in a Saudi Arabian university context. Members of the professional development unit responsible for the supervision of over 200 teachers in a Saudi Arabian university were interviewed. After qualitative analysis, three themes emerged: (1) Teacher Resistance (2) Willingness to listen to teachers (3) Standardization. The themes are discussed with the focus on how they help us determine which models of supervision influence the participant supervisors the most.

Key words: Professional development models, Classroom observations, Teacher education, Accountability.

\section{Introduction}

The aim of this article is to critically analyze the changing nature of professional development models and the supervisor/supervisee working relationship. "Supervisor" here is used for people in managerial positions within institutions whose job is to ensure that teaching is up to standard. We will use this rather simplistic definition for now for the sake of brevity as we will be looking more closely at how the concept of "supervision" and 'supervisor" has been defined in literature later in the article. It is no secret that the working relation between teachers and supervisors has always been an uneasy one and literature on teacher education and supervision is teeming with references to its troublesome nature (Aubusson, Steele, Dinham, \& Brady, 2007; Bailey, 2006; Borich, 1994; Gebhard \& Oprandy, 1999; Kilbourn, Keating, Murray, \& Ross, 2005) It has been labeled a „private cold war" by Blumberg (1980). This might sound surprising at first. According to Day (1999)(p. 2), "Continuing, career-long professional development is necessary for all teachers in order to keep pace with change and to review and renew their own knowledge, skills and visions for good teaching". Defining professional development, he states "[It] consists of all natural learning experiences and those conscious and planned activities which are intended to be of direct or indirect benefit to the individual, group or school and which contribute, through these, to the quality of education in the classroom" (Day, 1999) (p. 2). If educational organizations are employing supervisors for the achievement of these desirable goals, why is there so much resistance on the part of teachers? Could it be that they do not want to develop professionally? Do they refuse to review and renew their knowledge? Do they want to remain stuck with "old-fashioned" and perhaps ineffective teaching methods? On the contrary, there is resistance from teachers because the genuine desire for professional development has the tendency to "dissipate into impracticable rhetoric at some stage during the translation from what is required to what is enacted" (Evans, 2008)(p. 23). We need to look at the object that is causing the tension in the supervisor/supervisee relation: activities and procedures aimed at professionalization and professional development.

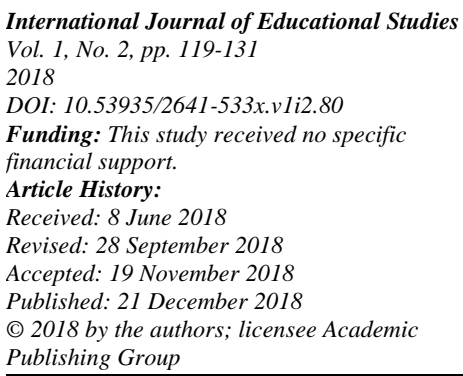

| 119 


\section{Literature Review}

What exactly is professional development? How does one develop professionally? What are the constituent elements of being a professional? As soon as we start thinking about these questions, it becomes clear that the concepts of developing professionally, being a professional, professionalism etc. are by no means easy to comprehend and be in agreement about. As Freidson (1994)(p.169) states, "much of the debate about professionalism is clouded by unstated assumptions and inconsistent and incomplete usages". The concept of professionalism is not used in a concrete way and is interpreted differently by different people (Fox, 1992). Indeed, the very title of Fox's paper gives us an indication of the ambiguity surrounding the concept of professionalism: „What do we mean when we say professionalism?" Hargreaves and Goodson (1996) also refer to the fact that there seems to be no consensus about the meaning of professionalism. The issue becomes even more confusing when we find that occupations as diverse as "secretaries, restaurant staff, security personnel, furniture retailers (among others) are all allegedly offering ,professional services” (Fournier, 1999)(p. 281). Having noted the nebulous nature of the idea of professionalism, we will now look at some general points that could be found consistently in definitions of professionalism and being a professional which could be useful in forming an understanding of the concept. According to Hargreaves (2000)(p.152), professionals have "a strong technical culture with a specialized knowledge base and shared standards of practice, a service ethic where there is a commitment to client needs, monopoly over service, long periods of training, and high degrees of autonomy". For Adams (2012)(p. 328) professionalism means "minimizing conflict, limiting emotional expression, enforcing dress codes, ordering work relationships, encouraging proficiency and knowledge, and instilling autonomy and responsibility", all of which presumably help make the work environment more pleasant. Hoyle (2001) (p. 146) states that the term professionalism is used "to describe enhancement of the quality of service". Another common theme in definitions of professionalism is that of social closure, whereby professionals try to maintain their interests regarding status and salary. Various studies (Macdonald, 1995; Witz, 1992) have analyzed the strategies of social closure and exclusion that professions deploy "to claim exclusive ownership of particular areas of expertise and to raise the status and prestige of their practice" (Fournier, 1999)(p. 282).

Many writers, though, do not view the concept of professionalism as an objective and neutral construct. Rather, it is merely a term used by people in positions of power to control and marginalize their subordinates and employees. As Adams (2012)(p. 328) states, "professionalism...serves to obscure and silence a variety of gender, occupation/profession, skill, race and class inequalities, raising concerns about for whom and to what ends professionalism serves" and later refers to "the use of professionalism as a disciplinary mechanism for socializing employees within strategically crafted occupational identitiese (p.331). Fournier (1999) (p. 281) calls ,the appeal to professionalism ...one of the strategies that is deployed to control the increasing margin of indeterminacy or flexibility in work". Evetts (2012), who wrote about three different interpretations of professionalism, said of the third interpretation that it was "ideological and used as a means of practitioner/employee control" (p.11).

At this point, it would be very useful to view (Evans, 2002, 2008) of the constituent elements of professional development.

According to Evans's description, there are two elements of professional development. One of the elements is described as „functional development", referring to performance improvement. Within functional development, she describes two foci of change: (a) procedural development, referring to the improvement in the procedures utilized at work and (b) productive development, referring to improvement in how much people produce or do at work. The other element of professional development is described as „attitudinal development", referring to the modification of people's attitudes toward their work. Within attitudinal development, two foci of change are described: (a) intellectual development and (b) motivational development, which, as their names suggest, refer to intellectual and motivational improvement respectively. The crucial point here is that any kind of appeal or demand for professionalism, either from within the profession to be better able to serve the clientele or from the government as a requirement, is likely to focus on functional development, which is tangible and measurable, as opposed to attitudinal development. Yet, functional development only accounts for partial development and is therefore destined for limited success. Not all activities and responsibilities lend themselves to clerical and numerical enumeration and evaluation. There are many components that cannot be reduced to rating scales and numbers on a performance evaluation

Vol. 1, No. 2, pp. 119-131

2018 Funding: This study received no specific

Article History:

Revised: 28 September 2018

Accepted: 19 November 2018

Published: 21 December 2018

(0) 2018 by the authors; licensee Academic

Publishing Group

| 120 
form, such as trust, creativity, innovation etc. Ultimately, all that remains under focus are the means for functional development. Evetts makes this point most cogently when she states:

The imposition of targets in teaching and medical work...have had 'unintended' consequences on the prioritization and ordering of work activities, and have brought with them a focus on target achievement to the detriment or neglect of other less-measurable tasks and responsibilities. Increased regulation and form filling takes time which might arguably be devoted to clients. The standardization of work procedures, perhaps using software programs, is an important check on the underachieving practitioner but can be a disincentive to the creative, innovative, and inspirational professional. (2012, p. 21)

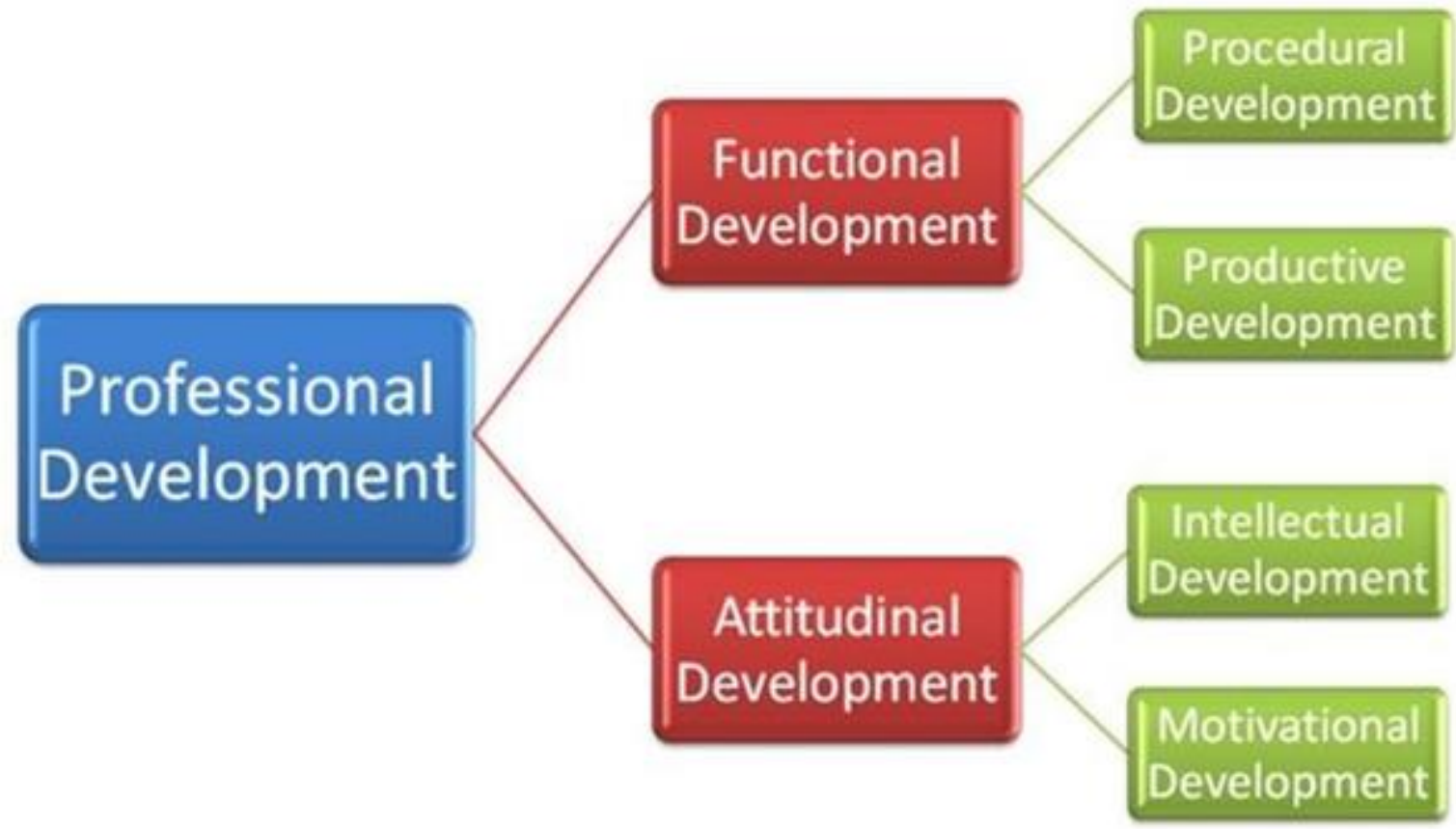

Figure-1. Constituent elements of professional development according to Evans (2008).

Managerial demands/requirements for professionalism can easily have unintended consequences. If professionalism is described as target achievement and exhibition of certain actions prescribed by management, an 'audit culturee is created in which the services of professionals are evaluated and enumerated, leading to the commodification of their services (Svensson \& Evetts, 2003) and thereby, "necessitating supervision, assessment and audit" (Evetts, 2012)(p. 22). Referring to this issue, Evetts further states:

Attempts to measure and demonstrate professionalism actually increase the demand for explicit auditing and accounting of professional competences. Thus, managerial demands for quality control and audit, target setting and performance review become reinterpreted as the promotion of professionalism. (2012, p. 22)

Top-down approaches which ignore the real meaning and purpose of professionalization and professional development and instead adhere to "the age-old rituals of visitation, judgment, and prescription" (Garman, 1986)(p.

148) will most likely be of limited value. It is the microscopic focus on the means of functional development that led Hoy and Forsyth (1986) to conclude: "Most supervisory programs are piecemeal and eventually degenerate into meaningless rituals required by law and/or boards of education" (p.50). Under such an approach, there is usually the feeling of being oppressed on the part of the teachers and the feeling of insubordination felt by the supervisors. Activities and procedures aimed at professionalization and professional development are sometimes met with resistance by teachers, who could get a feeling of disempowerment because of the way those activities and procedures are implemented as the „social relationships" being enacted in these situations are influenced by top- down and factory driven notions (Smyth, 1988). One of the reasons for this innately adversarial situation is that historically, educational 
supervision has been directly influenced by the assembly line supervision model used in factories to control subordinates (Woolfolk \& Hoy, 1990). A glance at the definitions of "supervision" and "supervisor" in literature in the last few decades can help illustrate this. According to Beach and Reinhartz (2000) supervisors" primary role is to examine and analyze teaching behaviors in order to make recommendations regarding instructional improvement. Acheson and Gall (1992) describe supervision as "an emphasis on improving teachers" classroom performance" and that supervisors "should take responsibility for helping teachers develop ... a broader repertoire of teaching skills and techniques" (1992, p. 1). Daresh (2001) (p. 25) says that "supervision is a process of overseeing the ability of people to meet the goals of the organization in which they work". Embedded in such definitions is the assumption that people in managerial positions are somehow superior to teachers and that their knowledge and beliefs about teaching are more legitimate and closer to the truth, which is not always the case. Bailey states:

Teacher supervision [is] a profession that many teachers enter almost by accident. Teachers can be promoted into supervisory positions for many reasons: they are excellent teachers, they have experience, they have "people skills," they are seen as loyal to the administration, they have seniority, and so on. Seldom are teachers made supervisors because they have had specific professional preparation for the role. (2006, p.xiii)

After analysing ten books on supervision published between 1985 and 1995, Reitzug (1997) (p. 326) asserted that "The analysis yielded images that primarily portrayed the principal as expert and superior, the teacher as deficient and voiceless, teaching as fixed technology, and supervision as a discrete intervention". These traditional views of supervision perpetuate "the imbalance of power by placing administrators and other nonteaching personnel in supervision roles and by combining evaluation with supervision" (Showers, 1985)(p. 47). However, not all models of supervision are mere „transplants" of the assembly line model. In this regard, professional development and supervision models have seen a change along a continuum: earlier models of supervision tended to be more directive and top-down, but there has been a constant move away from models that cast the supervisor in an inspector's role toward models where the supervisor's role is more collegial. The last quarter of the twentieth century has seen a shift in "that teachers - not supervisors - both take the responsibility for improving their teaching and decide how such improvements are made" (Bailey, 2006))(p. 381). We will now review how some authors have defined different models of supervision in the last three or four decades. It must be noted that the boundaries between different supervision models or even different categories within one supervision model could be fuzzy at times and there is some overlap between models and categories. In addition, mutual exclusivity is not an inevitable corollary of adherence to one model or category. It should also be noted that this is not intended to be an exhaustive list of all supervision models but only a brief review of some of the models which outline different approaches to supervision.

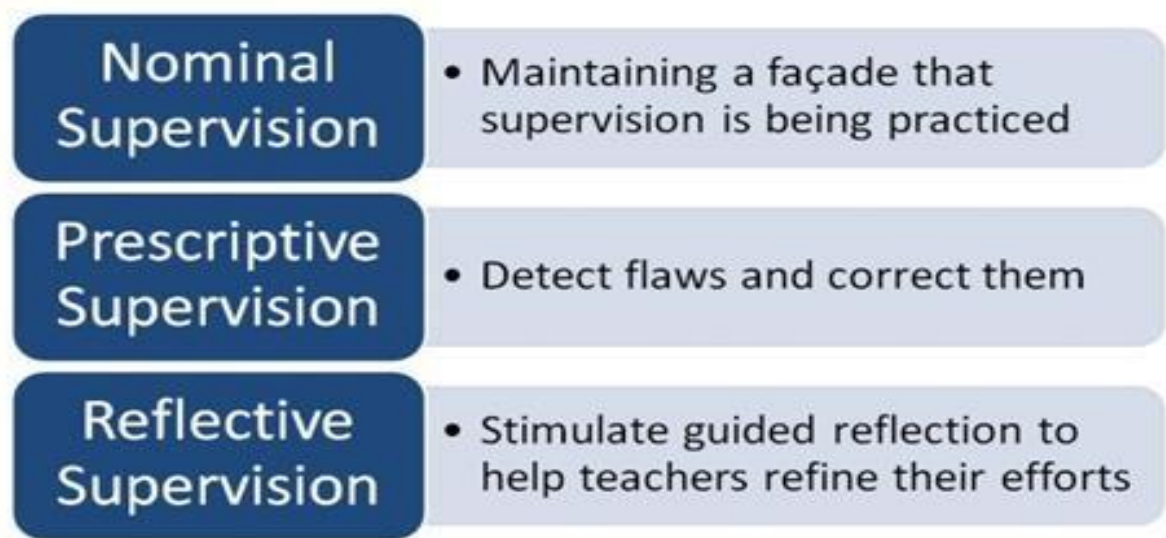

International Journal of Educational Studies Vol. 1, No. 2, pp. 119-131

Figure-2. Goldsberry"s three models (1988).

Of the three models described by Goldsberry, it can be seen that the third one places the teacher in a position of relative parity with the supervisor. However, according to Goldsberry, it is used less often than either the nominal model or descriptive model. 


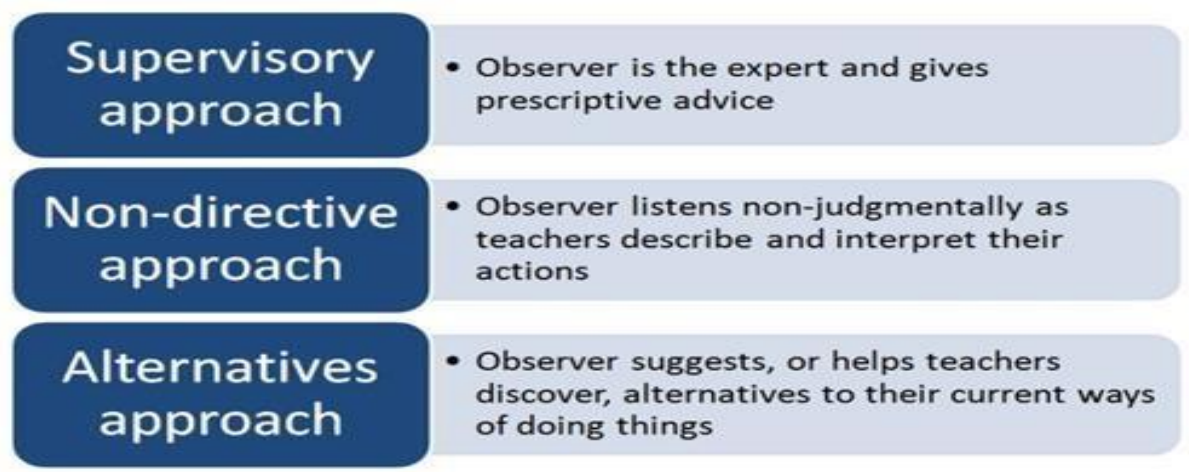

Figure-3. Freeman"s approach to observation and feedback (1989).

The supervisory approach in Freeman's categories is in the traditional and top-down end of the continuum of supervisory models whereas the non-directive and alternatives approach are more towards the collegial end of the continuum.
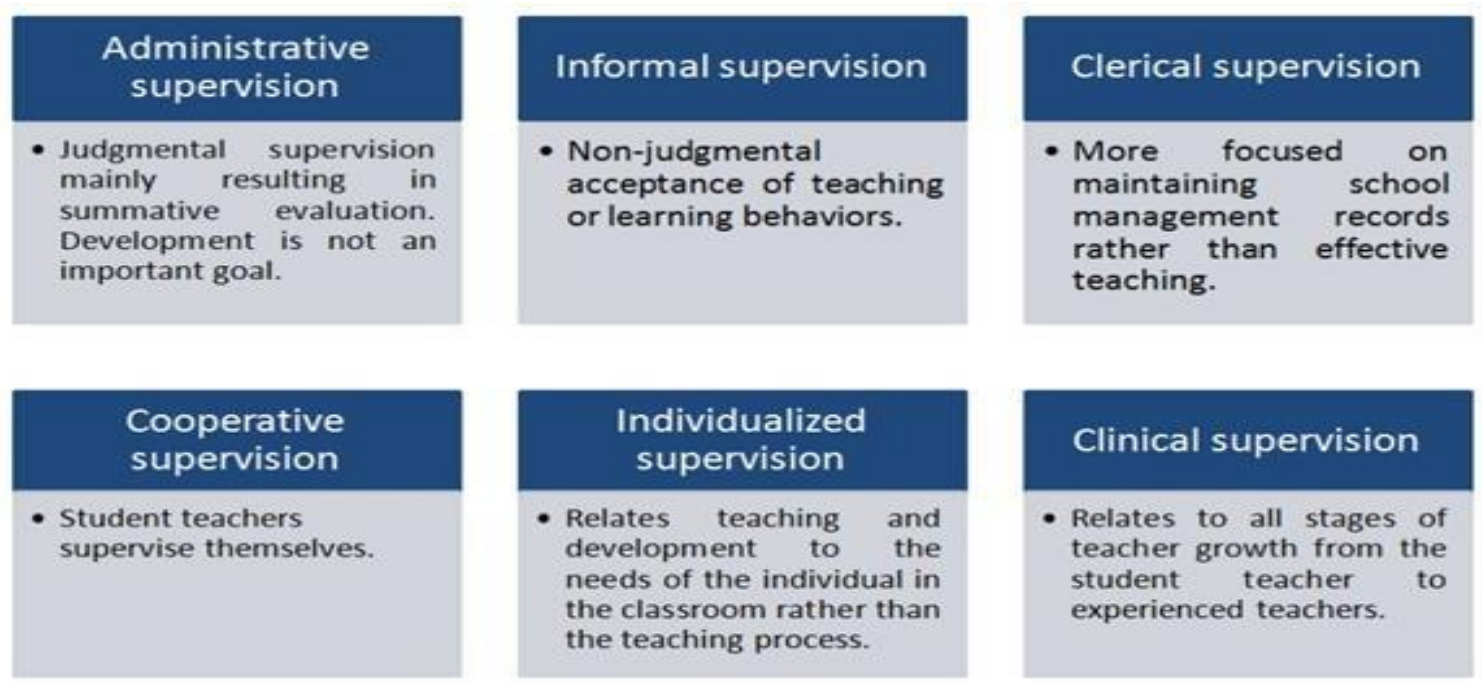

\section{Clinical supervision}

- Relates to all stages of teacher growth from the student teacher to experienced teachers.

Figure-4. Clarke"s six roles of pre-service teacher supervisors (1990).

In Clarke's view, the latter three roles lead to real professional development. They are also the ones which give the teachers a more active role in the supervisory process, as their names indicate. Clarke's leaning toward the more collegial roles is a product of the times as the field of supervision has been constantly moving toward more democratic forms of supervisor/teacher working relations.

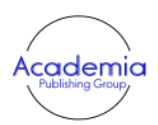

International Journal of Educational Studies Vol. 1, No. 2, pp. 119-131

2018

DOI: $10.53935 / 2641-533 x . v 1 i 2.80$

Funding: This study received no specific

financial support.

Article History:

Received: 8 June 2018

Revised: 28 September 2018

Accepted: 19 November 2018

Published: 21 December 2018

() 2018 by the authors; licensee Academic

Publishing Group

| 123
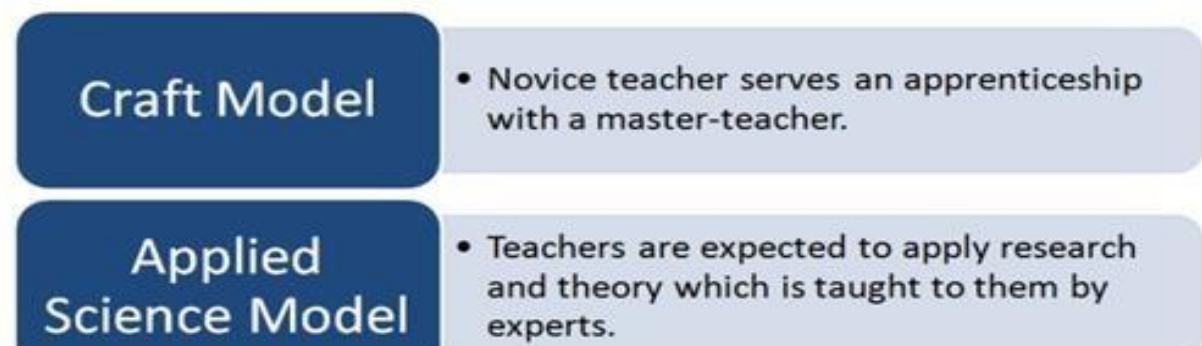

- Teachers are expected to apply research and theory which is taught to them by experts.

\section{Reflective Model}

- Recognizes the influence of research and the experiential knowledge of teachers.

Figure-5. Wallace (1991). 
As in Goldsberry's three models, the third model described by Wallace, the 'Reflective Model ${ }^{\text {ee }}$ places the teacher in a relatively more autonomous position by taking into account their learning backgrounds and professional experience. Wallace prefers the third model because "the responsibility for the development of professional expertise is seen as essentially residing with the trainee, by a process of reflecting on his or her own practice" (Wallace \& Woolger, 1991)(p. 321). He states that it could probably be more rewarding despite being more demanding. Once again, his preference for the more collegial of the models is consistent with the general trend in the shift toward more collegial models of supervision.

\section{McGrath's Model (1997)}

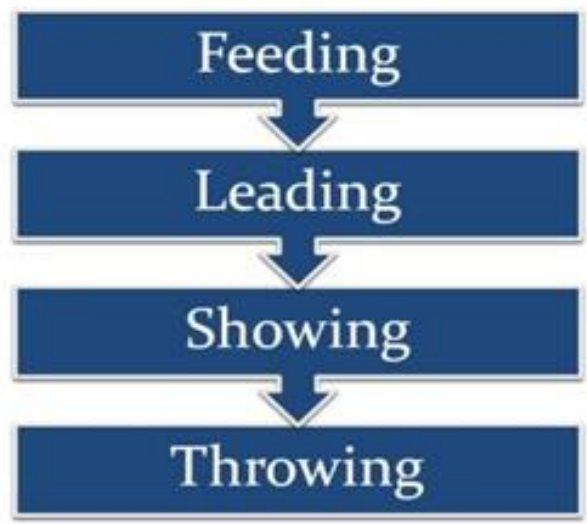

The Joyce and Showers Model (2002)

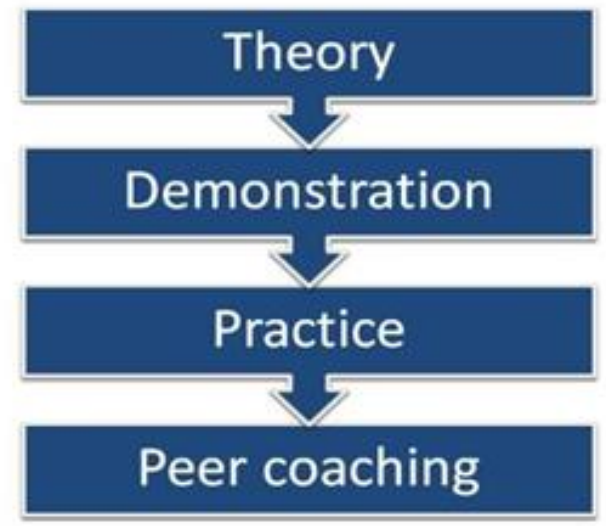

Figure-6. Comparison of McGrath (1997) and the Joyce and Showers (2002).

The Joyce \& Showers Model and McGrath"s approach to supervision and professional development are different from the descriptions of the other authors mentioned before them in this paper. The others were descriptions of different models, whereas Joyce \& Showers and McGrath describe steps within one model. They are very similar to each other, with the first three steps in The Joyce and Showers Model corresponding with steps one, three and four of McGrath"s model. Theory/Feeding is the first step, where the trainer gives input. Demonstration/Showing refers to the stage where the trainer models the ideas taught in step one. Practice/Throwing is the practical stage of "learning/getting better by doing" (McGrath, 1997)(p. 169). The second step in McGrath"s model, leading, is an awareness raising stage, a bridge between step one and three. Both models are developmental in nature, with no emphasis on summative evaluation. Therefore, both are purely for professional development or developmental supervision. The interesting thing about McGrath"s model and an important reason for mentioning it in this paper is his idea of „division of labor". According to him, all the stages, from Feeding to Throwing could be fronted by trainees (with varying degrees of support from the trainer). This is diametrically opposite to „Applied Science Model" described by Wallace (1991) where the input is supposed to come from distant "experts" and „researchers" who are not teaching themselves. In McGrath"s model, the "division of labor between those who know about teaching and those who do it" (Smyth, 1991)(p. 16) does not exist, or is much less pronounced than in other models. When Gebhard and Oprandy (1999) assert that supervision can lead to a deeper awareness of teaching for both teachers and supervisors, we see once again a departure from top-down approaches to professional development. Smyth (1988) is rather blunt in expressing his dissatisfaction with top-down approaches to professional development. According to him, approaches where supervisors try to evaluate and prescribe teaching instead of empowering teachers and investing control of teaching in their hands have a lot in common with "the factory- derived notions of scientific management from whence they emanate" $(1988, \mathrm{p}$. 137). To emphasize his point, Smyth cites Frederick Taylor, who is credited with the development of "scientific management" as an idea. In his work, Taylor compares factory workers with an ox and states that because they are so stupid, they should be trained by a person more intelligent than them. Smyth goes on to state that although people "may not openly espouse such a degrading point of view, they are through their actions implicitly endorsing a way of working that is deeply embedded in Taylor's ideology" (Smyth, 1988) 
(p. 137). Chamberlin (2000) also comments on the shift from top-down and inspectional models of development to more collegial and democratic models:

The role of the supervisor has shifted from that of a detached expert to that of an engaged colleague who encourages teachers to talk about their work and reflect on their practice in a new way. The supervisor, once viewed mainly as an expert evaluator, is now charged with the responsibility of gaining teachers" trust and creating an environment that cultivates reflection, exploration, and change. (2000, p. 656)

\subsection{Research Question}

Which professional development models form the basis of the beliefs and activities of supervisors in the context of the current study?

\subsection{Significance of the Study}

In the literature review, I outlined the changing nature of professional development models. The trend is a shift away from top-down models toward collegial models. The aim of this research is to investigate to what extent, or even if, this trend has affected aspects of my professional context because most of the literature cited in the first part is from a North American context. Writing about the shift in supervisors" roles from inspectional to collegial models, Bailey (2006) (p. 17) says that "the extent of this change depends on the culture [and] the trend is by no means universal". This is a crucial point to be considered because there is no guarantee that trends witnessed in one part of the world will necessarily be witnessed in another part of the world or in a different context. Building on the same topic, Bailey states:

We must remember that changes in language teacher supervisors" roles do not occur at the same pace or move in the same direction everywhere (emphasis added). The supervisor's role is, in part, culturally defined and conceptually located in the educational and political history of a particular region. (2006.p.6)

Supervisory procedures and systems differ from each other according to cultures and contexts and no two supervisory situations are the same. In some unfortunate situations, the whims and vagaries of the supervisor are the „supervisory system", whereby he/she makes decisions and demands without being answerable and accountable to anyone. Sometimes, the tension in the supervisor/supervisee relation arises from the way the supervisory system is constructed or implemented; sometimes, it is because of the personality and mental makeup of one or more of the people in supervisory positions.

There is a need for research studies that investigate the influence of mainstream professional development models in different contexts. This research study aims to contribute to the literature in the field of professional development by letting the participants of the study articulate their beliefs in order to allow the researcher to investigate how the participants viewed their roles and the extent to which they were influenced by inspectional or collegial models of professional development.

\section{Methodology}

The current study is located within the interpretive paradigm and all of the steps were influenced by an interpretive outlook. The aim was to conduct a fine-grained study about supervisors" beliefs and perspectives, which could be explored best with an interpretive methodology. All four members of the professional development unit who supervise over two hundred teachers in a foundation year program in the men"s section of a university in Saudi Arabia were chosen. Below is a table with some basic information about the supervisors.

International Journal of Educational Studies Vol. 1, No. 2, pp. 119-131 
Table-1. Demographic information of the participant supervisors

\begin{tabular}{|l|l|l|l|}
\hline Participant & Nationality & $\begin{array}{l}\text { Teaching Qualifications } \\
\text { (Degree - Training) }\end{array}$ & Teaching Experience \\
\hline Supervisor 1 & American & MA TESOL - Train the trainer course & 10 years \\
\hline Supervisor 2 & Pakistani & MA English - CELTA & 15 years \\
\hline Supervisor 3 & British & MA Applied Linguistics - PGCE & 20 years \\
\hline Supervisor 4 & Pakistani & MA Linguistics \& Literature - CELTA & 5 years \\
\hline
\end{tabular}

Interviews were used to collect data from the participant supervisors. The interview data was subjected to qualitative analysis. The data were coded and the codes were collapsed under three themes, which are discussed in detail below.

\section{Findings and Discussion}

In the setting of the current study, the supervisory system as it exists at the time of writing was initially implemented purely for evaluative reasons. It was the management"s way of carrying out summative evaluations for the purpose of contract renewal/termination or transfers to rural campuses. In the four or five years since its inception, the supervisory system has changed dramatically, with more and more emphasis being placed on developmental aspects.

Not only have there been changes in the classroom observation system, but also in the number of professional development activities, with more workshops and focus group discussions. In addition, a mentoring program was started to provide opportunities for teachers who want to seek assistance at any time during the year, not just in the observation and workshop „season". On the surface, because of the changes mentioned above, it appears that in its very brief life, the supervisory system in the setting of the current study looks like the landscape of supervision in microcosm: It started for evaluation and quality control but is now gradually becoming more developmental. The evaluative aspect still remains with the end of the year formal observations, but that is now just one element of the system, not the sum of it. However, one question needs to be asked here: Is the developmental aspect indeed what it claims to be or it is there merely for cosmetic purposes? Is it possible that all the talk about development is only lip-service? Smyth writes:

The rhetoric of supervision is compelling enough, couched as it is in terms of "improvement of teaching" through a collaborative process of consultation, observation, analysis, and feedback. Terms like "mutual trust," "collegiality," and "teacher autonomy" are seductive nomenclature....Contradiction becomes apparent when we preach collegiality, collaboration, and teacher autonomy, while imposing clinical supervision upon teachers. (1991, p. 47)

Thornbury (1996) writes about his suspicion that many teachers who claim to be proponents of the Communicative Approach are in fact only paying lip-service to it and do not follow the tenets of CA in practical classroom situations. Is the same statement applicable for the supervision system of under discussion in this article? With this caveat in mind, I will discuss the three themes that emerged after qualitative analysis, with the focus on how these themes help us determine which models of supervision influence the participant supervisors most. These themes are:

(1) Teacher Resistance

(2) Willingness to listen to teachers

(3) Standardization 


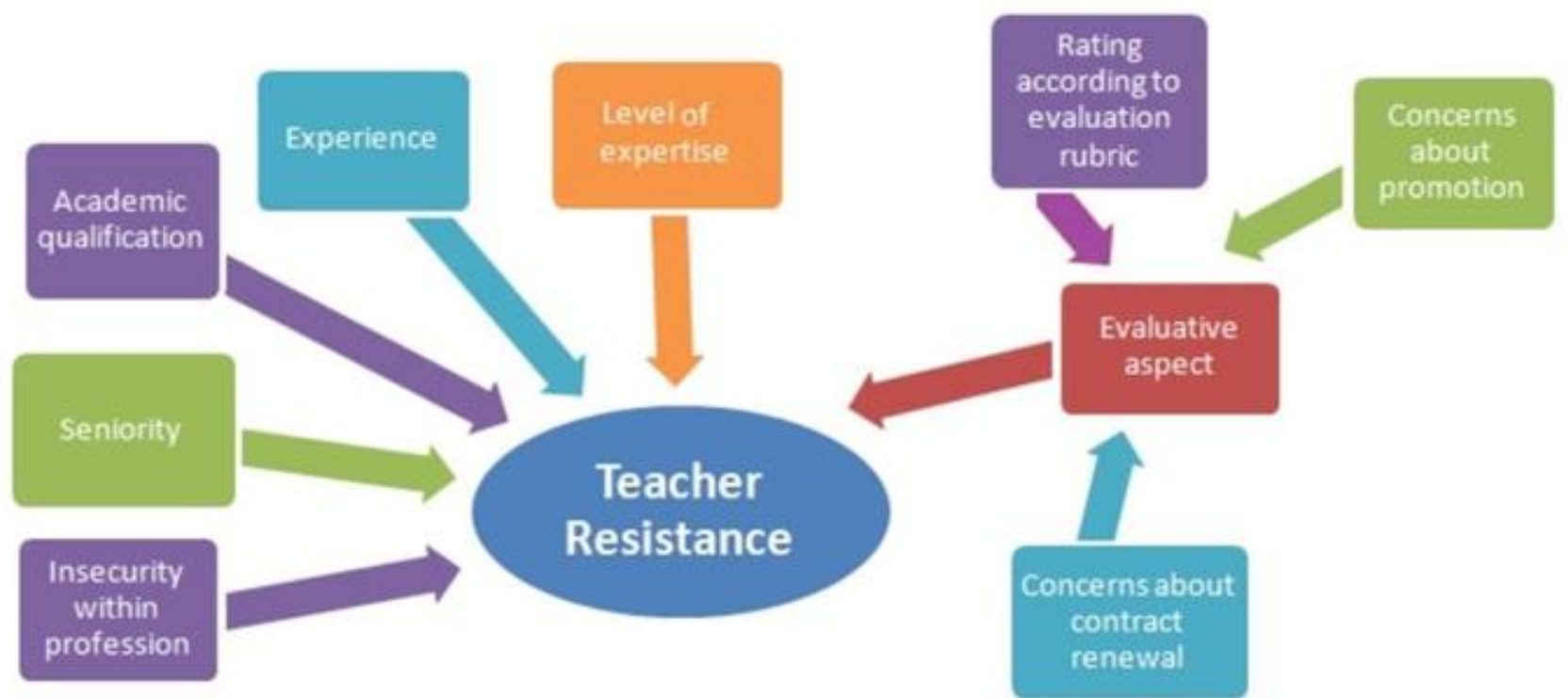

Figure-7. Visual representation of the first theme, teacher resistance, together with the codes and categories that were discussed under it.

This was a major theme that kept recurring at all stages in data collection. According to the participant supervisors, the biggest reason for teacher resistance was the evaluative aspect of the professional development unites work. Because of concerns about their jobs and status within the institution, teachers reacted to professionalization activities in different ways, sometimes leading to disagreement between supervisors and supervisees. As stated previously, the primary function of the supervision team initially was to evaluate teachers. Despite all the changes in the recent past which saw the supervision team tasked with more developmental activities, the evaluative aspect looms large in the minds of teachers, which affects how they react to professionalization activities. The supervisors interviewed for this study did not think that teacher resistance was due to stubbornness or refusal to engage in intellectual enquiry. Teachers were mostly concerned about their jobs and once the evaluative aspect was taken away, there was much less resistance. When professionalization activities had no summative bearing, the supervisor/supervisee interaction dynamic changed and the working relation became much more collegial. Apart from the evaluative aspect, supervisors felt that resistance could also be because of different factors related to the supervisee"s academic background. Teachers who were more qualified and experienced than the supervisor or had been in the institution longer than the supervisor were more resistant to trainer feedback. Conversely, in some cases, it was because of their lack of experience or training. These perceptions of the supervisors about teachers were different from the ones referred to in Sergiovannies article nearly thirty years ago. In that study, it is stated that supervisors spoke to the editor of their state Association for Supervision and Curriculum Development journal about problems they faced, and mentioned (among other things) that "teachers don't think rationally enough, don't plan, are not responsive to criticism, and are unable to see reality" (Sergiovanni, 1985)(p. 5). Judging only by their views about teachers, it can be seen that the supervisors cited in Sergiovanni"s article are more influenced by top-down models of supervision. They might have had the students" best interest at heart when they tried to make teachers "see reality", but the question that begs to be asked is: Who decides what constitutes students" best interests? Reitzug states:

Frequently those in power (e.g., principals, supervisors) position their interpretation of reality as the only correct interpretation, and alternative interpretations are viewed as inappropriate, counterproductive, or wrong. In the supervisory process, therefore, teachers and supervisors may interpret quite differently the teaching that best meets the interests of particular students. (1997, p. 330)

In the current study, supervisors appeared to be more influenced by collegial models when it came to reacting to teacher resistance. There was more flexibility than rigidity because at all stages, they manifested willingness to listen to the teachers" points of view and use their ideas to make amendments in the supervisory

Vol. 1, No. 2, pp. 119-131

2018

Funding: This study received no speci

financial support.

Received: 8 June 20

Revised: 28 September 2018

Accepted: 19 November 2018

() 2018 by the authors; licensee Academic

Publishing Group

| 127 
procedures. The only time supervisors felt helpless in dealing with teacher resistance was when teachers totally refused to engage in dialogue. One of the reasons which prevented teacher/supervisor conflict from escalating was the supervisory system itself which provided guidelines for situations where there is disagreement between the teacher and the observer. There is an appeal system outlined in writing whereby the teacher submitted the points of disagreement to the head of the professional development unit, who would then assign a different supervisor to observe that teacher"s class. The new observer has no access to the previous report and has no knowledge about the previous rating. This mechanism lifted the pressure off both the teacher and the supervisor. They both know that they do not have to fight tooth and nail to prevail. The very existence and structure of the appeal system indicates that the supervisory system is influenced by collegial models of professional development because it provides teachers with an official channel to express disagreement with supervisors.

\section{Theme-2: Willingness to Listen to Teachers}

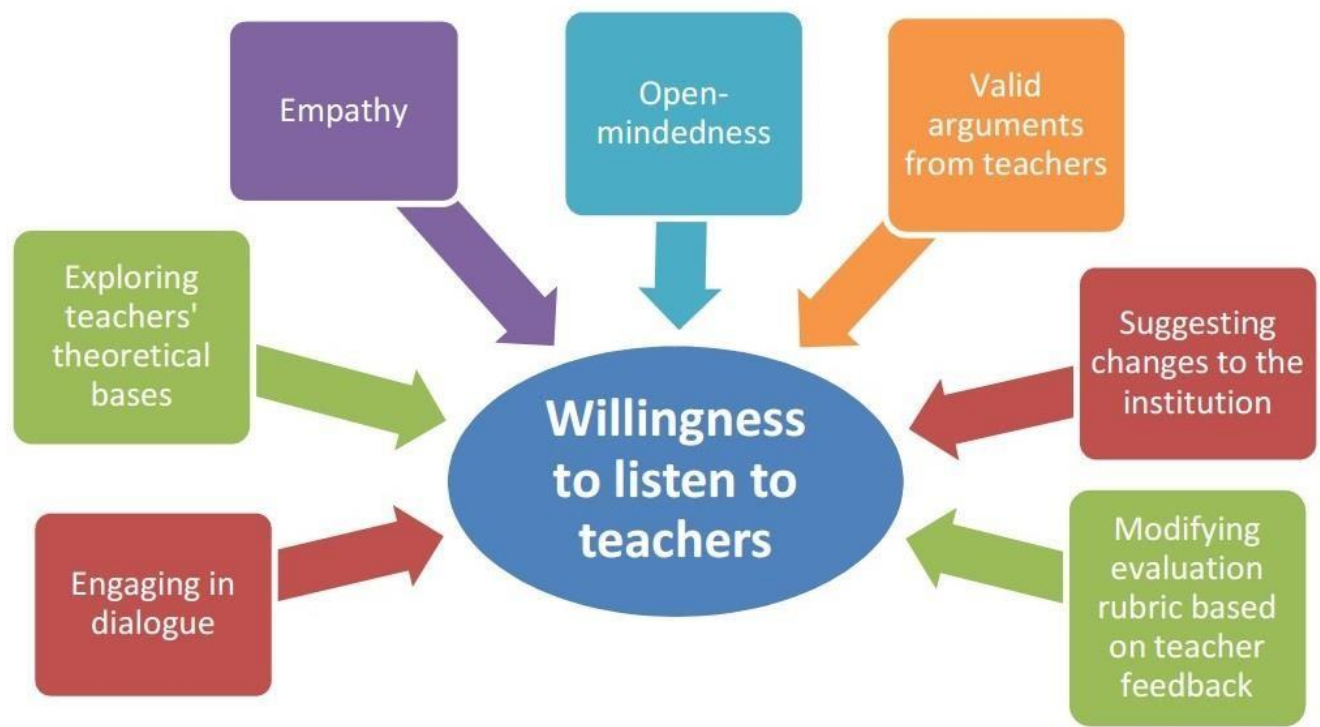

Figure-8. Visual representation of the second theme, Willingness to Listen to Teachers, together with the codes and categories that were discussed under it.

This theme served to mitigate the previous one. When supervisors managed to convince teachers that they were not anchored to their ideas and that the goal of discussion was not to force them to accept the supervisor" views, it helped make the supervisory conferences friendlier and more about academic points instead of subjective arguments. The participant supervisors manifested a willingness to engage in dialogue with the teachers at all stages of data collection. Bailey states:

It is important for supervisors to listen carefully to teachers" ideas and to try to understand the causes of resistance. Since there is so little hard evidence about effective teaching, we must acknowledge that there is often more than one good way to reach an instructional goal.

Listening to teachers" ideas is one step toward overcoming resistance. (2006, p. 280)

While acknowledging that they had to observe and rate lessons according to a yardstick provided by the institution (the evaluation rubric), the participant supervisors emphasized that the rubric was not set in stone and teachers" feedback can certainly be used to make changes in the rubric and in the supervisory system itself. Evidence from the recent past suggests that this was more than just hollow rhetoric. In the space of one calendar year, many changes were made in the supervisory system to make it more just for the teachers: (1) The addition of optional pre- observation meetings in the observation cycle. (2) Requiring all teachers to make developmental plans at the end of the year which are followed up next year. (3) Initiating a mentoring program. (4) Sharing the detailed evaluation criteria with teachers prior to the observation, so that teachers know exactly what the observers were required to look at. (5) Sharing model lesson plans with the teachers. (6) Making available videos of lessons that receive high scores in the evaluation report. (7) Standardization of

International Journal of
Vol. 1, No. 2, pp. 119-131

Funding: This study received no specific

financial support.

Received: 8 June 2018

Revised: 28 September 2018

Published: 21 December 2018

(0) 2018 by the authors: licensee Academic

Publishing Group 
observation procedures. (8) Restructuring of post-observation conferences based on recommendations from supervision literature. (9) Various modifications in the evaluation rubric.

This is a departure from the trend described by Reitzug (1997). After analysing ten books on supervision published between 1985 and 1995, he concluded: "In summary, the images described in supervision textbooks portray teachers as mindless and voiceless individuals who should respond robotically to supervisor commands" (p.333). In this theme, it can be seen once again that the participant supervisors were more influenced by collegial models of supervision in their willingness to make changes based on teacher feedback. This attitude does not view the teacher as a voiceless recipient of expert advice but an active partner in the learning process whose concerns will not be brushed aside as an indication of insubordination. One reason for the collegiality of the participant supervisors is that they are not far removed from teaching themselves, and therefore, are in a better position to understand the plight of teachers. In the setting of the current study, the preparatory year English language program is divided into four modules, with each module consisting of six or seven weeks of instruction. Supervisors are required to teach for at least one or two modules every year. Staying in touch with the classroom has a significant effect on supervisors and prevents them from making unreasonable and unrealistic demands from teachers. This is in direct contrast to the top-down „Applied Science Model ${ }^{\text {ee }}$ described by Wallace (1991). He asserts that in its extreme form, the „Applied Science Modele $^{\text {ee }}$ is basically one-way in which experts who are removed from day to day practice report research findings to practitioners, whose responsibility it is then to implement these findings. "If the trainees fail, it is perhaps because they haven"t understood the findings properly, or because they have not properly applied the findings, or whatever" (Wallace, 1991) (p. 9). He further states that the tendency of the "experts" to be far removed from day to day working scene is more pronounced in teaching than in other professions and he cites medicine as an example where a surgeon could have a high academic reputation and still be engaged in performing surgery on a daily basis.

In the setting of the current study, the requirement that participant supervisors be engaged in teaching for some modules every academic year has the effect of making them more collegial and inclined to empathize with teachers as the memories of being a teacher and the problems faced in the day to day practice are always fresh in their minds.

\section{Theme-3: Standardization}

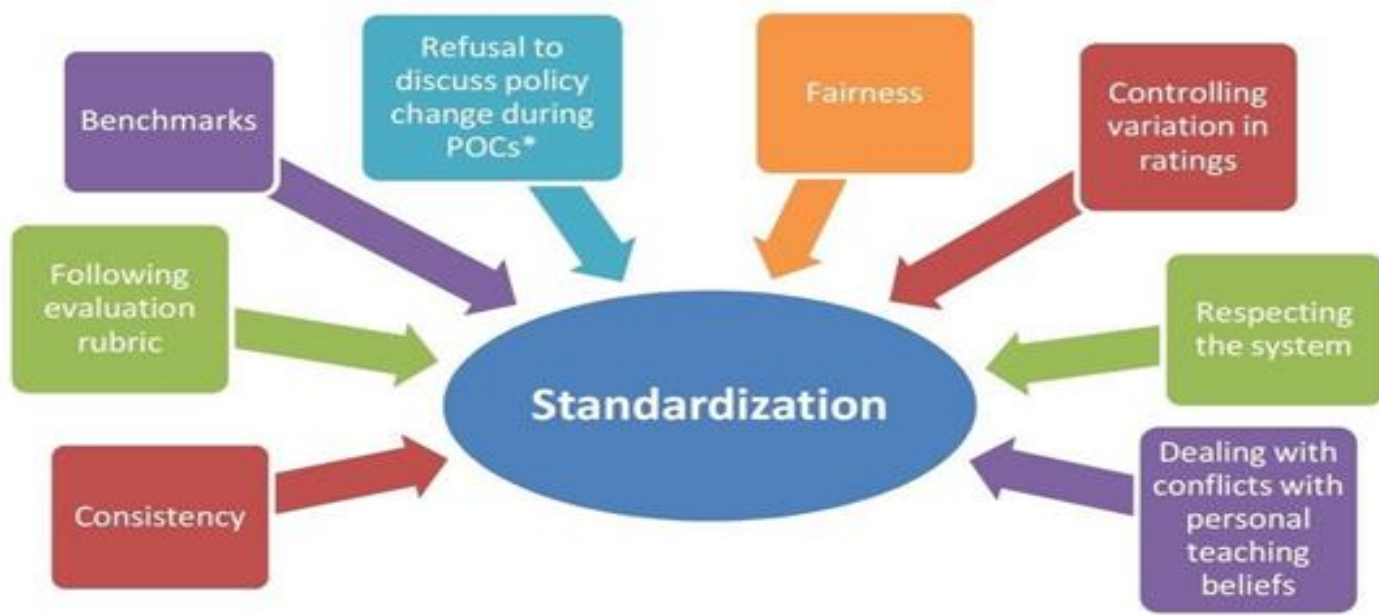

Figure-9. Visual representation of the third theme, standardization, together with the codes and categories that were discussed under it

International Journal of Educational Studies Vol. 1, No. 2, pp. 119-131

In the last theme, I discussed how supervisors exhibited a willingness to listen to valid arguments from teachers and suggest changes to the institution based on their feedback. As Supervisor 3 said: "Just because the observee disagrees with the rubric or the observer doesn't mean that he or she is wrong. I will collect data from him or her for suggesting changes to the institution". At the same time, the participant supervisors were quick to point out that they cannot adopt a laissez-faire approach. They cannot go against the supervisory system and they cannot deviate from the evaluation rubric in place at the time of rating observed lessons, 
whether they are developmental or evaluative. In the setting of the current study, the same supervisory system is used across four campuses. Any change in any part of the system has to be agreed upon by all four campuses, which are then implemented in all of the them. This process is not straightforward, I was informed by the head of the professional development unit, as sometimes there is consensus in the men"s campus about some change but the women"s campus does not agree to it and vice versa. The view of the participant supervisors was that if an individual supervisor working on his own deviates from the supervisory system outlined in the faculty handbook and the evaluation rubric, it would lead to too much variation in ratings within the professional development unit. Supervisor 1 said:

We are dealing with over 500 teachers across campuses. We need to be able to come to the administration and say that the teachers have been evaluated relatively equally. In [a program of] this size, it"s going to be impossible for it to be completely equal. You cannot do a multiple choice question about teaching. There se always going to be some level of subjectivity. That"s our reason for sticking to the rubric as opposed to somebody"s opinion.

After highlighting examples of teacher-deficit assumptions in supervision books, Reitzug states: [It is] not [being] suggest[ed] that principals should adopt a laissez-faire attitude toward teaching. However, a distinct difference exists between a perspective that assumes something is wrong with a teacher's teaching and a perspective that recognizes teaching as a complex endeavor that requires continual study. (1997, p.331)

In the current study, participant supervisors voiced their opinion that the institution has taken great pains to set up a supervisory system which is adhered to across campuses. In fact, the institution invited a trainer from one of the highest ranking universities in the world to train the professional development unit, with the visiting trainer requested to focus on „standardization". In a one week intensive training program, professional development unit members observed lessons together with the visiting trainer, rated the lessons individually according to the evaluation rubric provided by the institution immediately after the lesson and discussed their ratings and the logic behind the ratings. The aim was to articulate their believes in the presence of an expert so that there could be clarity and agreement about the items on the evaluation rubric. The supervisors stressed that to be fair to all the teachers, they had to ensure that all of them are rated according to the same yardstick. In the description of the first theme, Teacher Resistance, I mentioned that the participant supervisors felt that the evaluative aspect of their work was the biggest reason for teacher resistance. In my opinion, their stringent adherence to the evaluation rubric could also be one of the reasons for teacher resistance. Garman (1986) (p. 154) states that adherence to a single model of teaching coupled with the refusal of intellectual inquiry is "the most insidious form of pretense and quackery in supervision". It must be mentioned, though, that the supervisory system in the setting of the current study is at a particular stage in its evolution at the time of writing and this is not the ,final product ${ }^{\text {ee }}$, as some supervisors pointed out. As stated previously, the participants were always willing to take aboard teacher feedback to modify the supervision system and the evaluation rubric and it cannot be said that they refuse to engage in intellectual inquiry. Based on this theme, it is hard to determine which models of supervision the participants are influenced by. If stringent adherence to the supervisory system is only and only for the sake of fairness and consistency on the demands of the administration with a sincere commitment to change in case valid arguments are brought forward, then it can be said that the participants are influenced by collegial models of supervision. However, if the participants view the evaluation rubric as a safety net for them which absolves them from the responsibility of using their own intellectual faculties, then they are just cogs in a top-down supervisory machine. The constant assertions of the participants regarding willingness to make changes inclines me to think that they are more influenced by collegial models, but to develop a more informed opinion, further data is required regarding their personal feelings of having to work within the confines of the evaluation rubric and their reaction when the evaluation rubric clashes with their own teaching beliefs. Although these points were touched upon during the interviews, the data is not sufficient enough to draw conclusions about them.

\section{Conclusion}

The aim of the study was to determine which models of supervision the participant supervisors are mostly influenced by. The data suggests that the global trend of the shift away from inspectional to collegial models could be detected in the context of the current study as the supervisors appeared to be more influenced by collegial models of supervision regarding most points, not just by their assertions but by tangible changes over 


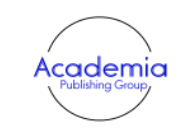

International Journal of Educational Studies Vol. 1, No. 2, pp. 119-131

2018

DOI: $10.53935 / 2641-533 x . v 1 i 2.80$

Funding: This study received no specific

financial support.

Article History:

Received: 8 June 2018

Revised: 28 September 2018

Accepted: 19 November 2018

Published: 21 December 2018

(C) 2018 by the authors; licensee Academic

Publishing Group

131 the last few years. There was a little rigidity in the adherence to the evaluation rubric for rating observed lessons, but the participants emphasized that it was an organizational requirement to ensure consistency and fairness. They admitted that the system was not perfect. There were many things which needed improvement and they were willing to make changes if practical suggestions were put forward, although it was not an easy task because there had to be a consensus in all four campuses before any changes could be implemented.

\section{References}

Acheson, K. A., \& Gall, M. D. (1992). Techniques in the clinical supervision of teachers (3rd ed.). New York: Longman.

Adams, K. F. (2012). The discursive construction of professionalism: An episteme of the 21st century. Ephemera, 12 (3), 327.

Aubusson, P., Steele, F., Dinham, S., \& Brady, L. (2007). Action learning in teacher learning community formation: Informative or transformative? Teacher Development, 11(2), 133-148.

Bailey, K. M. (2006). Language teacher supervision: A case-based approach. New York: Cambridge University Press.

Beach, D. M., \& Reinhartz, J. (2000). Supervisory leadership: Focus on instruction. Boston, MA: Allyn and Bacon.

Blumberg, A. (1980). Supervisors and teachers: A private cold war (2nd ed.). Berkeley, CA: McCutchan.

Borich, G. D. (1994). Observation skills for effective teaching. Columbus, OH: Merrill.

Chamberlin, C. R. (2000). TESL degree candidates' perceptions of trust in supervisors. Tesol Quarterly, 34(4), 653-673. Available at: https://doi.org/10.2307/3587780.

Daresh, J. C. (2001). Supervision as proactive leadership (3rd ed.). Prospect Heights, Illinois: Waveland Press.

Day, C. (1999). Developing teachers: The challenges of lifelong learning. New York: Falmer Press.

Evans, L. (2002). What is teacher development? Oxford Review of Education, 28(1), 123-137.

Evans, L. (2008). Professionalism, professionality and the development of education professionals. British Journal of Educational Studies, 56(1), 20-38.

Evetts, J. (2012). Professionalism in turbulent times: Changes, challenges and opportunities. Paper presented at the ProPel International Conference, Stirling, UK.

Fournier, V. (1999). The appeal to „professionalismee as a disciplinary mechanism. The Sociological Review, 47(2), $280-307$.

Fox, C. J. (1992). What do we mean when we say" professionalism?": A language usage analysis for public administration. The American Review of Public Administration, 22(1), 1-17.

Freidson, E. (1994). Professionalism reborn: Theory, prophecy, and policy. London, UK: University of Chicago Press.

Garman, N. B. (1986). Clinical supervision: Quackery or remedy for professional development. Journal of Curriculum and Supervision, 1(2), 148-157.

Gebhard, J. G., \& Oprandy, R. (1999). Language teaching awareness: A guide to exploring beliefs and practices. Cambridge, England: Cambridge University Press.

Hargreaves, A. (2000). Four ages of professionalism and professional learning. Teachers and Teaching: Theory and Practice, 6(2), $151-182$.

Hargreaves, A., \& Goodson, I. F. (1996). Teachers' professional lives: Aspirations and actualities. In I. F. Hargreaves, A. and Goodson, I.F. (1996). Teachers' professional lives: Aspirations and actualities. In I. F. Goodson \&AHargreaves (Eds.), Teachers' professional lives (pp. 1-27). London, UK: Falmer Press.

Hoy, W. K., \& Forsyth, P. B. (1986). Effective supervision: Theory into practice. New York: Random House.

Hoyle, E. (2001). Teaching: Prestige, status and esteem. Educational Management \& Administration, 29(2), $139-152$.

Joyce, B. R., \& Showers, B. (2002). Student achievement through staff development. Alexandria, VA: Association for Supervision and Curriculum Development.

Kilbourn, B., Keating, C., Murray, K., \& Ross, I. (2005). Balancing feedback and inquiry: How novice observers (supervisors) learn from inquiry into their own practice. Journal of Curriculum and Supervision, 20(4), 298-318.

Macdonald, K. M. (1995). The sociology of the professions. Thousand Oaks, CA: Sage.

McGrath, I. (1997). Feeding, leading, showing, throwing: Process choices in teacher training and trainer training. In I. McGrath (Ed.), Learning to train: Perspectives on the development of language teacher trainers (pp. 162-172). Hemel Hempstead, England: Prentice Hall.

Reitzug, U. C. (1997). Images of principal instructional leadership: From super-vision to collaborative inquiry. Journal of Curriculum and Supervision, 12(4), 324-343

Showers, B. (1985). Teachers coaching teachers. Educational Leadership, 42(7), 43-48.

Smyth, J. (1988). A "critical" perspective for clinical supervision. Journal of Curriculum and Supervision, 3(2), $136-156$.

Smyth, J. (1991). Teachers as collaborative learners: Challenging dominant forms of supervision. Buckingham, UK: Open University Press.

Svensson, L., \& Evetts, J. (2003). Conceptual and comparative studies of continental and Anglo-American professions (Research Report No. 129). Gothenburg University.

Thornbury, S. (1996). Paying lip-service to CLT. EA Journal, 14(1), 51-63.

Wallace, M. J. (1991). Training foreign language teachers: A reflective approach. London, UK: Cambridge University Press.

Wallace, M. J., \& Woolger, D. (1991). Improving the ELT supervisory dialogue: The Sri Lankan experience. ELT Journal, 45(4), 320327.

Witz, A. (1992). Patriarchy and professions. London, UK: Routlede.

Woolfolk, A. E., \& Hoy, W. K. (1990). Prospective teachers' sense of efficacy and beliefs about control. Journal of Educational Psychology, 82(1), 81-91. Available at: https://doi.org/10.1037/0022-0663.82.1.81. 